\title{
Drug utilisation evaluation in patients with osteoarthritis in tertiary care hospital
}

\author{
Abdul Rasheed, Mohammed Muneebullah, Mohammed Maqsood, \\ Arbaz Ahmed Khan, Mohamed Ahmed*
}

Department of Pharmacy Practice, Shadan College of Pharmacy, Hyderabad, Telangana, India

Received: 26 November 2021

Revised: 08 January 2022

Accepted: 10 January 2022

*Correspondence:

Mohamed Ahmed,

Email: moin086@gmail.com

Copyright: ( $)$ the author(s), publisher and licensee Medip Academy. This is an open-access article distributed under the terms of the Creative Commons Attribution Non-Commercial License, which permits unrestricted non-commercial use, distribution, and reproduction in any medium, provided the original work is properly cited.

\begin{abstract}
Background: The principle aim of our study is to assess the prescribing pattern of drugs used in treatment of osteoarthritis patients.

Methods: A prospective and empirical study was carried out at department of orthopaedics-Shadan teaching and general hospital, for 6 months.

Results: During the study period, a total 120 patients were enrolled, of which $57 \%$ were females, $43 \%$ were males and common age group was $\geq 60$ years. It was found that $56 \%$ of OA patient have history of trauma and $62 \%$ of obese individual contribute to occurrence of OA. It was found that subjects developed comorbidities like CV disorders which is $36 \%$. It was found that $63 \%$ have OA for a duration of $>2$ years, $56 \%$ had no knowledge about their medications, $59 \%$ have co-morbidity, $61 \%$ have treatment complexity. NSAID's, calcium, vitamin $\mathrm{D}_{3}$, glucosamine and chondroitin sulphate were the most frequently prescribed drugs in OA accounting for $50 \%$. It was reported that $55 \%$ were adherent to OA medication, adherence to physical activity was $64 \%$, adherence to weight loss was $62 \%$.

Conclusions: Our study manifest that majority of the patients had duration of $>2$ years of OA. The reasons for the uncontrolled pain was due to absence of awareness about osteoarthritis-related difficulties, drugs, low calcium diet, increased stress, obesity, and advanced age. Continuous health education, patient counselling, information about medication adherence and satisfaction at follow-ups is essential to avoid the problems.
\end{abstract}

Keywords: Osteoarthritis, Drug utilization study, NSAID’s, Clinical pharmacist

\section{INTRODUCTION}

Drug utilization evaluation (DUE) is a continuous, systematic, and criteria-based programme of medicine evaluations that will assist in ensuring optimal medication use. If therapy is found to be ineffective, providers or patients will need to be involved in order to optimize pharmacological therapy. ${ }^{1}$ Drug utilization review (DUR) is typically classified into three different categories: prospective DUR, concurrent DUR and retrospective DUR. ${ }^{2}$ The most frequent type of arthritis is osteoarthritis (OA) and symptomatic OA is recognized as an important reason of disability and participation restriction in middle-aged and older adults. OA is a heterogeneous condition confined to synovial (diarthrodial) joints. ${ }^{3}$

\section{Osteoarthritis}

Osteoarthritis is a progressive degenerative disorder that occurs due to the bio-chemical break-down of articular 
cartilage (hyaline) in synovial joints. The entirety of the joint organ, including the sub-chondralbone and synovium, is affected. ${ }^{4}$

\section{Clinical presentation}

Pain's the most prominent feature and the most prevalent type of presentation of osteoarthritis. ${ }^{5}$ In osteoarthritis, stiffness in the morning typically lasts less than 20 minutes. Advanced OA disease is associated with subluxation of the joint and gross deformity. Knee osteoarthritis is common. Unlike rheumatoid arthritis, osteoarthritis affects only one knee compartment (patellofemoral, medial, or lateral) and isn't symmetrical. ${ }^{6,7}$

\section{Risk factors}

Risk factors are depicted in (Figure1).

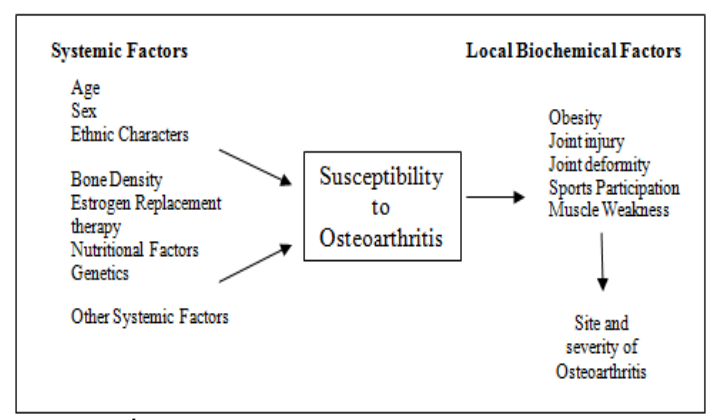

Figure 1: Pathogenesis of osteoarthritis with putative risk factors. ${ }^{8}$

\section{Diagnosis}

X-ray evaluation is the "gold standard" in the diagnosis of osteoarthritis. Measurement of cartilage degradation components in serum, urine, or joint fluid has sparked a lot of attention recently, because identifying signs of early cartilage breakdown could lead to earlier diagnosis and management. ${ }^{8}$

\section{Treatment}

The therapeutic goals for OA patients are to educate patient about the condition and to maintain freedom and quality of life by reducing or eliminating knee pain, restoring joint mobility, reducing inflammation, improving surrounding muscle strength to protect knee structures, Each OA patient's treatment is determined by the location and severity of joint involvement, comorbid illness conditions, concurrent medication, and allergies. ${ }^{9}$ There is still no cure for $\mathrm{OA}$ at this time. In general, nonpharmacological, pharmacological, and surgical interventions are used to treat OA. Non-Pharmacological treatments: exercise and physiotherapy are advised for all stages of OA regardless of age, comorbidities, pain severity, or impairment. ${ }^{10}$ However, exercise alone is not always or always not effective as a treatment for OA.

Table 1: Current recommended OA drugs by AAOS, ACR, and OARSI. ${ }^{11}$

\begin{tabular}{|c|c|}
\hline Drugs & Recommendations \\
\hline Acetaminophen & $\begin{array}{l}\text { AAOS: Inconclusively } \\
\text { recommended for symptomatic knee } \\
\text { OA with } 3000 \text { mg per day } \\
\text { (moderately recommended in the } \\
2008 \text { edition with up to } 4000 \mathrm{mg} \text { per } \\
\text { day) ACR: First-line drug up to } \\
4000 \text { mg per day OARSI: An } \\
\text { effective initial oral analgesic for } \\
\text { mild-to-moderate OA pain up to } \\
4000 \text { mg per day. }\end{array}$ \\
\hline $\begin{array}{l}\text { Non-selective } \\
\text { NSAIDs }\end{array}$ & $\begin{array}{l}\text { AAOS: Strongly recommended for } \\
\text { symptomatic knee OA ACR: } \\
\text { Conditionally recommended for } \\
\text { hand, knee, and hip OA OARSI: } \\
\text { Recommended for patients with } \\
\text { symptomatic hip or knee OA at the } \\
\text { lowest effective dose. }\end{array}$ \\
\hline $\begin{array}{l}\text { Selective COX- } \\
2 \text { inhibitors }\end{array}$ & $\begin{array}{l}\text { AAOS: Strongly recommended for } \\
\text { symptomatic knee OA ACR: } \\
\text { Conditionally recommended for } \\
\text { hand, knee, and hip OA OARSI: } \\
\text { Recommended for patients with } \\
\text { symptomatic hip or knee OA at the } \\
\text { lowest effective dose. }\end{array}$ \\
\hline $\begin{array}{l}\text { Opioid } \\
\text { analgesics } \\
\text { (tramadol) }\end{array}$ & $\begin{array}{l}\text { AAOS: Strongly recommended for } \\
\text { symptomatic knee OA ACR: } \\
\text { Conditionally recommend for hand, } \\
\text { knee, and hip OA OARSI: Consider } \\
\text { use for the treatment of refractory } \\
\text { pain in patients with hip or knee OA. }\end{array}$ \\
\hline $\begin{array}{l}\text { SNRIs } \\
\text { (duloxetine) }\end{array}$ & $\begin{array}{l}\text { AAOS: Not included ACR: } \\
\text { Conditionally recommended for } \\
\text { patients } \geqslant 75 \text { OARSI: Not included. }\end{array}$ \\
\hline $\begin{array}{l}\text { Intra-articular } \\
\text { corticosteroids }\end{array}$ & $\begin{array}{l}\text { AAOS: Inconclusively } \\
\text { recommended for symptomatic knee } \\
\text { OA ACR: Conditionally } \\
\text { recommended for hip and knee OA } \\
\text { OARSI: For patients with moderate- } \\
\text { to-severe pain who are not respond } \\
\text { to oral analgesic and anti- } \\
\text { inflammatory agents. }\end{array}$ \\
\hline $\begin{array}{l}\text { Intra-articular } \\
\text { hyaluronic acid }\end{array}$ & $\begin{array}{l}\text { AAOS: No longer recommended } \\
\text { (inconclusively recommended in the } \\
2008 \text { edition) ACR: No } \\
\text { recommendation OARSI: May be } \\
\text { useful in patients with knee or hip } \\
\text { OA. }\end{array}$ \\
\hline
\end{tabular}

ACR-American college of rheumatology; AAOS-American academy of orthopaedic surgeons; NSAIDs-non-steroidal antiinflammatory drugs; OA-osteoarthritis; OARSI-Osteoarthritis research society international; SNRIs-serotonin-norepinephrine reuptake inhibitor. 
Pharmaceutical treatments for $\mathrm{OA}$ are being considered in this case. Surgical treatment should always be the last resource for OA treatment. ${ }^{9}$ Pharmacological treatment: presently, there are no drugs that effectively are able to modify the disease process in OA (that is, treatment that will reduce symptoms in addition to slowing or stopping the disease progression). ${ }^{12}$ Surgery: Surgery is an invasive procedure that should be used if non-pharmacological and pharmacological treatments have failed to produce the intended results. For end-stage hip or knee OA a joint replacement is an effective treatment option. ${ }^{13}$

\section{METHODS}

\section{Study design, location, duration and sample size}

Current study is a prospective observational study. During study tenure, a prospective study looks for outcomes, such as the development of a disease, and correlates this with other factors, such as a potential risk or protection factor(s). Prospective studies offer the advantage of having fewer possible sources of confounding and bias. The study was conducted at the Shadan institute of medical sciences, teaching hospital \& research centre, a tertiary care hospital, Hyderabad. The data required was obtained from the orthopedics department. Data was gathered on osteoarthritis on a daily basis during the study period, as well as during follow-up visits. The study was conducted for duration of 6 months from January 2021 to June 2021. 120 patients were enrolled in the current study.

Table 2: Inclusion criteria and exclusion criteria.

\begin{tabular}{|ll|}
\hline Inclusion criteria & Exclusion criteria \\
\hline $\begin{array}{l}\text { Patients willing to } \\
\text { involve/participate in the } \\
\text { study }\end{array}$ & $\begin{array}{l}\text { Patients not } \\
\text { involving/willing to } \\
\text { participate in the study. }\end{array}$ \\
\hline $\begin{array}{l}\text { Patients with history of } \\
\text { osteoarthritis with or } \\
\text { without co-morbidities. }\end{array}$ & $\begin{array}{l}\text { Patients with Asthma and } \\
\text { COPD. }\end{array}$ \\
\hline
\end{tabular}

\section{Study procedure}

Data was gathered on osteoarthritis on a daily basis during the study period, as well as during follow-up visits in orthopedics department of the hospital. The collected data were recorded in data collection forms designed for the recording of only those factors/parameters vital to establish the objectives of the study. The data collection form used for the study was designed on Google drive, after which, it was entered month wise into Microsoft excel. The results were obtained after filtering for the required data, figures and percentages.

\section{Sources of data}

All necessary required and relevant data were collected from the orthopedics department in tertiary care hospital.
The data was collected from: patient's case notes, patient's prescribed prescription, in a questionnaire and laboratory reports. To find the prevalence of osteoarthritis and summarize the pattern of drugs prescribed in osteoarthritis patients. All the patients (with joint and knee pain) admitted in orthopaedics department of Shadan institute of medical sciences, teaching hospital \& research centre are screened for osteoarthritis. Each subjects detailed information/history regarding age, gender, body weight, employment-status, family-income, education, marital-status, socioeconomic status, urban or rural setting, date of admission, date of discharge, sleep pattern, physical-activity, dietary-intake, saltconsumption, laboratory investigations, history of osteoarthritis, and its treatment given, social habits, and any co-morbid conditions were collected. Literatures, which support the study, were obtained, and prescribing pattern of osteoarthritis drugs was reviewed.

\section{Statistical analysis}

The data were analyzed using descriptive statistics. Microsoft Word and Microsoft Excel were used to create the graphs and tables. To arrive at to our study's findings, we employed basic percentage calculations

\section{RESULTS}

A total of 120 patients (68 Females, 52 males) were enrolled in the study. Age-wise distribution of patients based on their joints involved, prescribed pattern of drugs is osteoarthritis patients, prescribed pattern of combinations of classes of drugs in osteoarthritis patients, participant adherence status on self-care behaviours among osteoarthritis patients were as mentioned in results.

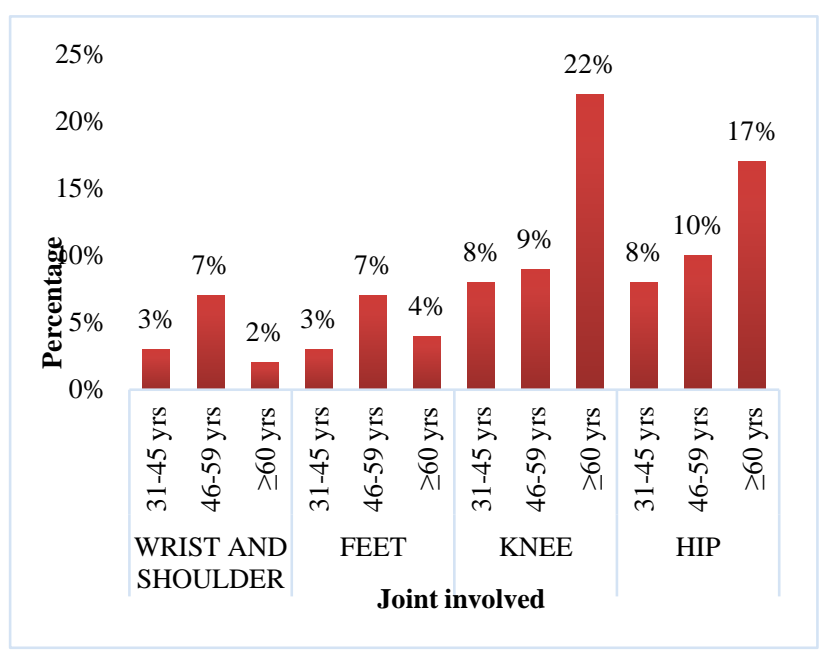

Figure 2: Age wise distribution of patients based on their joint involved in osteoarthritis.

Majority of the patients were found to be belonging to the age group of $\geq 60$ years with Osteoarthritis affecting their knee joint significantly which accounts for $22 \%$. From 
the data obtained it was found that NSAIDs were the most commonly prescribed class of drugs in osteoarthritis. From the data obtained, it was found that a combination therapy of NSAIDs, calcium and vitamin $\mathrm{D}_{3}$, glucosamine, chondroitin sulphate was the most regularly prescribed therapy in osteoarthritis accounting for $50 \%$. It was found that $55 \%$ of patients were adherent to OA medication, $64 \%$ patients were performing physical activities/exercises and $62 \%$ of patients were adherent to losing weight.

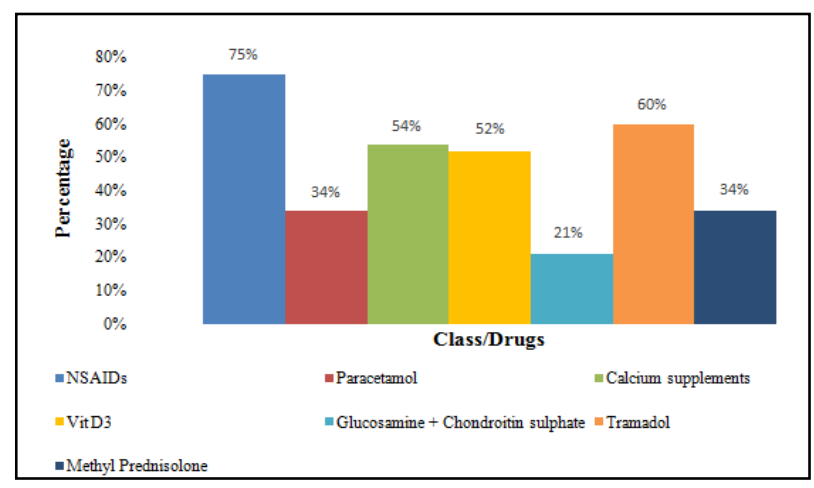

Figure 3: Prescribed pattern of drugs in osteoarthritis patients.

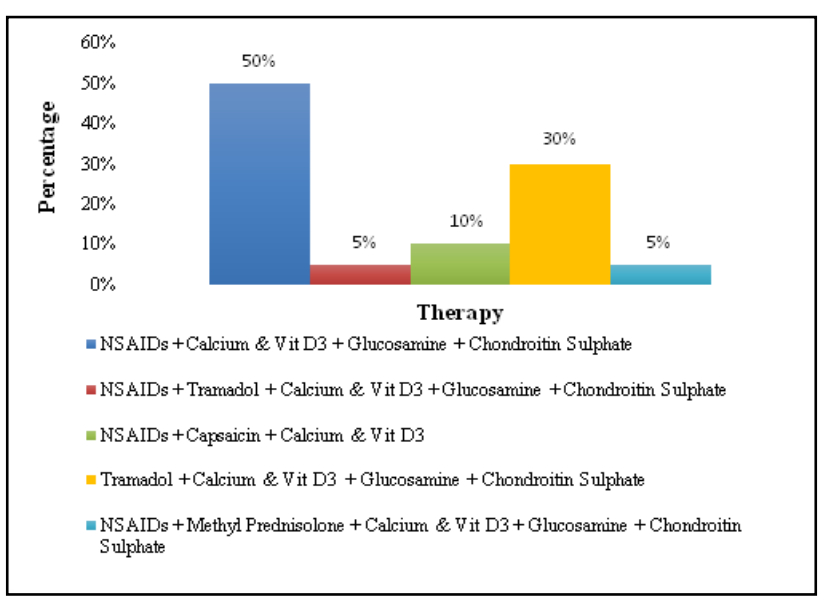

Figure 4: Prescribed pattern of combinations of classes of drugs in osteoarthritis patients.

\section{DISCUSSION}

In 120 patients that were included in the study, it was found that Knee joint was the most significantly affected joint, which accounted for $22 \%$ of the cases. This is comparable to a study by Oliveria et al. ${ }^{14}$ In our study, numerous kinds of medicines were prescribed, with NSAIDs (75\%) being the most typically prescribed, both in monotherapy and combined therapy followed by tramadol $(60 \%)$ calcium supplements $(54 \%)$, vitamin $\mathrm{D}_{3}$ $(52 \%)$, paracetamol $(34 \%)$, glucosamine and chondroitin sulphate in combination (21\%), methyl prednisolone $(34 \%)$ and also in the pattern of prescribing in osteoarthritis patients, NSAID'S were most commonly prescribed (75\%) and aceclofenac was the most frequently prescribed drug (52\%). This is comparable to a study by Gupta et al. ${ }^{15}$ In the study conducted, it was found that combination therapy of NSAIDS, calcium and vitamin $\mathrm{D}_{3}$, glucosamine, chondroitin sulphate was the most regularly prescribed therapy in osteoarthritis accounting for $50 \%$. In the study, it was found that $55 \%$ of patients were adherent to OA medications, $64 \%$ were performing Physical activities and $62 \%$ of patients were adherent to Losing weight. The adherence observed in the present study is higher than what has been reported in a similar study by Dominick et al. ${ }^{16}$

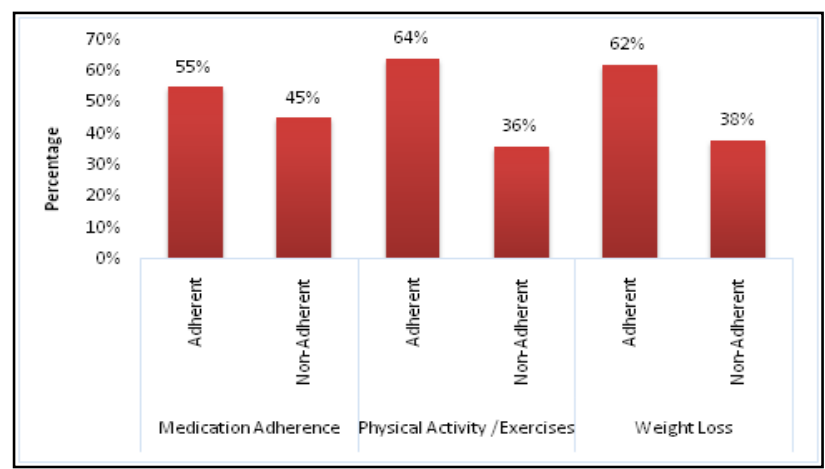

Figure 5: Participant adherence status on self-care behaviour among osteoarthritis patient.

\section{Limitations}

Limitations of current study was due to the Coronavirus pandemic follow ups were difficult as visits to the hospital were limited and as the study duration was only of 6 months, the sample size was limited to 120 patients.

\section{CONCLUSION}

Our study manifest that majority of the patients had duration of $>2$ years of OA. The reasons for the uncontrolled pain in Patient's was caused due to absence of awareness about osteoarthritis-related difficulties, drugs, a low calcium diet, increased stress, obesity, and advanced age. A clinical pharmacist can assess risk factors early on, improving the patient's quality of life and lowering the cost of medication. Continuous health education, patient counselling, and information about medication adherence and satisfaction at each follow-up is essential to avoid the problems

\section{ACKNOWLEDGEMENTS}

Authors would like to thank all who contributed towards the preparation and compilation of current research investigational study.

Funding: No funding sources

Conflict of interest: None declared

Ethical approval: The study was approved by the Institutional Ethics Committee 


\section{REFERENCES}

1. WHO Essential medicine list. Available at: https://en.wikipedia.org/wiki/WHO_Model_List_of_ Essential_Medicines. Accessed on 20 September 2021.

2. Robert N. Managed care pharmacy practice. 2nd edition.USA: Jones \& Bartlett Learning; 2008.

3. Dalbeth HN. Oxford Textbook of Osteoarthritis and Crystal Arthropathy. In: Michael D, Bijlsma J, David NA eds. 3rd ed. United Kingdom: Oxford Press;2009:3-4.

4. Medicine Information. Available at: emedicine. medscape.com/article/330487-overview. Accessed on 20 September 2021.

5. Creamer P, Hochberg MC. Why does osteoarthritis of the knee hurt--sometimes? Br J Rheumatol. 1997; 36(7):726-8.

6. Wollheim FA. Serum markers of articular cartilage damage and repair. Rheum Dis Clin North Am. 1999; 25(2):417-32.

7. Myers SL, Synovial fluid markers in osteoarthritis. Rheum Dis Clin North Am. 1999;25(2):433-49.

8. Felson DT, Lawrence RC, Dieppe PA. Osteoarthritis: new insights. Part 1: the disease and its risk factors. Ann Intern Med. 2000;133(8):635-46.

9. DiPiro JT. Pharmacotherapy: A pathophysiologic approach. New York: McGraw-Hill Medical; 2010.

10. Al-Omari B. Osteoarthritis and management. Orthoped Res J. 2019;5 (5):576-9.
11. Zhang W, Ouyang H, Dass C. Current research on pharmacologic and regenerative therapies for osteoarthritis. Bone Res. 2016;4:15040.

12. Yusuf E. Pharmacologic and non-pharmacologic treatment of osteoarthritis. Curr Treat Options Rheumatol. 2016;2(2):111-25.

13. Kloppenburg M, Berenbaum F. Osteoarthritis year in review 2019: epidemiology and therapy. Osteoarth Cartil. 2020;28(3):242-8.

14. Oliveria SA, Felson DT, Reed JI, Cirillo PA, Walker AM. Incidence of symptomatic hand, hip, and knee osteoarthritis among patients in a health maintenance organization. Arthritis Rheum. 1995;38(8):1134-41.

15. Gupta R, Malhotra A, Malhotra P. Study of prescription pattern of drugs used in the treatment of osteoarthritis in a tertiary care teaching hospital: an observational study. Int J Res Med Sci. 2019;6:985.

16. Dominick KL, Golightly YM, Bosworth HB. Racial differences in analgesic/anti-inflammatory medication adherence among patients with osteoarthritis. Ethn Dis. 2005;15(1):116-22.

Cite this article as: Rasheed A, Muneebullah M, Maqsood M, Khan AA, Ahmed M. Drug utilisation evaluation in patients with osteoarthritis in tertiary care hospital. Int J Basic Clin Pharmacol 2022;11:112-6. 